\title{
Child-Pugh Class Unknown
}

National Cancer Institute

\section{Source}

National Cancer Institute. Child-Pugh Class Unknown. NCI Thesaurus. Code C159867.

Unable to determine the Child-Pugh class. 